\title{
BMJ Open Survival analysis of 8785 malignant lymphoma cases in the oral and nasal cavities in the USA: a cohort study
}

\author{
Feifei Jiang (1) , Ai-Hui Yan
}

To cite: Jiang F, Yan A-H. Survival analysis of 8785 malignant lymphoma cases in the oral and nasal cavities in the USA: a cohort study. BMJ Open 2021;11:e048876. doi:10.1136/ bmjopen-2021-048876

- Prepublication history and additional supplemental material for this paper are available online. To view these files, please visit the journal online (http://dx.doi.org/10.1136/ bmjopen-2021-048876)

Received 13 January 2021 Accepted 08 November 2021
Check for updates

(C) Author(s) (or their employer(s)) 2021. Re-use permitted under CC BY-NC. No commercial re-use. See rights and permissions. Published by BMJ.

\section{Department of}

Otorhinolaryngology, The First Hospital of China Medical University, Shenyang, China

Correspondence to

Ai-Hui Yan;

yanmenxueshu@163.com

\section{ABSTRACT}

Objective To identify the factors associated with the survival of malignant Hodgkin and non-Hodgkin lymphomas in oral and nasal cavities.

Study design. Retrospective cohort survival analysis. Methods The Surveillance, Epidemiology and End Results 18 database was used to analyse the factors associated with the 5-year survival rate of malignant lymphomas diagnosed in the oral cavity and pharynx (OCP) and nasal cavity and sinus (NCS) regions from 1988 to 2011 for all patients in the USA. Multivariable Cox regression models were used to calculate the HR of malignant lymphoma death overall and by the site of cancer diagnosis. Results Among the 8785 patients included in the analysis, 4103 (46.7\%) were women, 6096 (69.4\%) were non-Hispanic (NH) white, 635 (7.2\%) were NH black and 1209 (13.8\%) were Hispanic patients of all races. We found that a higher 5-year survival rate of malignant lymphoma is associated with: female gender; younger age at diagnosis; NH white race/ethnicity; diagnosis in the oral cavity; receiving surgery/radiation and surgery/radiation, surgery and chemotherapy as the treatment; diagnosis at a localised stage and diagnosis in later calendar years. No association with lymphoma subtype was observed. Conclusion We have identified several demographics and prognosis factors associated with the 5-year survival rate of malignant lymphomas in the OCP and NCS regions. These findings warrant greater public health attention on the prognosis of malignant lymphomas in the OCP and NCS regions among the most vulnerable populations.

\section{INTRODUCTION}

Lymphomas are a group of malignant neoplastic proliferation of the immune system that can affect any organ in the body. They are traditionally categorised as Hodgkin lymphoma (HL) and non-HL (NHL) and each accounts for approximately $10 \%$ and $90 \%$ of all lymphomas, respectively. ${ }^{12}$ Similar to most cancers, the overall survival of lymphomas improves with younger ages and earlier stages at diagnoses. ${ }^{3}$ Malignant lymphomas in the oral and nasal cavities are rare, representing only $5 \%$ of all human lymphomas. ${ }^{4}$ However, a previous study has reported that the prognosis is poor, with a 5-year overall survival rate of $45 \%$ for malignant lymphomas diagnosed

\section{Strengths and limitations of this study}

The first study to use a population-based cancer registry with individual-level data to explore the survival of malignant lymphomas in the oral and nasal cavities.

- Inclusion of a large number of patients of multiple race/ethnic groups with medical coverage in the USA.

- Analysed the factors associated with malignant lymphoma survival with a Cox regression model adjusting for a set of relevant covariates to control for potential confounding.

- Studied the socioeconomic factors in association with malignant lymphoma survival.

- Residual confounding is likely due to the absence of covariates indicating viral infection (eg, EpsteinBarr virus, HIV, etc) and the detailed treatment methods, since the treatments have involved during the study timeframe from 1988 to 2011 in Surveillance, Epidemiology and End Results.

in the oral cavity and maxillofacial region among 151 patients of all ages. ${ }^{4}$

In general, the prognosis of NHL is worse than that of HL because NHLs are more likely to be diagnosed at advanced stages and older ages compared with HLs. ${ }^{5}$ In the USA, the median age of diagnosis is 39 years for HL and 69 years for NHL. ${ }^{6}$ NHLs can arise from $\mathrm{B}, \mathrm{T}$ or natural killer (NK) lymphocytes. ${ }^{7}$ Approximately $85 \%-90 \%$ of NHLs originate from B lymphocytes, and the remainder derives from T or NK lymphocytes. ${ }^{1}$ Immunosuppression is a well-established risk factor for NHL, as is Epstein-Barr virus (EBV). Associations have been reported between EBV and some NHL subtypes, including diffuse large B-cell lymphoma, Burkitt lymphoma and nasal NK/T-cell lymphoma. ${ }^{8}$

Chemotherapy is usually the initial treatment administered for NHL; radiation therapy may also be used for patients who are diagnosed at an early stage. Most patients respond well to the treatment. However, relapses are frequent, and many 
NHL subtypes are incurable with current management strategies. ${ }^{9}$ On the other hand, HLs are highly curable with combination chemotherapy, radiation or combined modality treatment, even when diagnosed in advanced stages. ${ }^{10}$ From 1975-2014, the relative 5-year survival rate for HLs improved steadily from $70 \%$ to $85 \%$, and the incidence of HLs decreased monotonically from 1.3 to 0.3 cases $/ 100000$ people in the USA. ${ }^{6}$ Immunosuppression, EBV and HIV are associated with the risk of HLs, but the aetiology of HLs is still not well understood. ${ }^{10}$

In the context of lymphomas diagnosed in the oral and nasal cavities, few studies have investigated prognostic factors despite the poor survival rate compared with lymphomas diagnosed at other sites. A study involving 151 participants with malignant lymphoma of the oral cavity and maxillofacial region reported that survival is associated with clinical stage, extranodal involvement, the presence of HIV and the presence of EBV. ${ }^{4}$ Another study, with 311 participants, also reported extranodal involvement as a risk factor for lymphomas diagnosed in the head and neck regions. ${ }^{5}$ In terms of treatment, a case series study reported that chemotherapy and radiation resulted in significantly higher survival rates than chemotherapy alone for lymphomas of the sinonasal tract. ${ }^{8}$ Overall, previous studies have been conducted with small groups of patients, which may not have sufficient statistical power to detect some prognostic factors. Therefore, a study that comprehensively evaluates the treatment, demographics and socioeconomic position (SEP) factors associated with the survival of lymphomas in the oral and nasal cavities is necessary to improve the prognosis of this disease.

\section{MATERIALS AND METHODS Study population}

We obtained information on patients diagnosed with malignant lymphoma at any age in the oral cavity and pharynx (OCP) and the nasal cavity and sinus (NCS) regions from the National Cancer Institute's populationbased Surveillance, Epidemiology and End Results (SEER) 18 database (1975-2016) Radiation/Chemotherapy Database. ${ }^{11}$ Cases diagnosed between 1998 and 2011 with complete information on the covariates were included in the analyses. The study period started in 1998 because information on surgery and cancer staging is available in the database from that year onwards. The study period ended in 2011 to allow for at least 5 years of follow-up for all cases.

\section{Variables}

Patients with known gender, age, race/ethnicity, cancer site, lymphoma subtype, treatment, cancer stage, year of diagnosis, county-level percentage of people with less than high school education in 2000 and county-level median household income were included in the analyses. The vital status was determined with the 'SEER cause-specific death classification' variable: patients whose deaths were attributable to this cancer within 5 years of diagnosis were deemed to be dead and otherwise deemed to be alive. Patients lost to follow-up were regarded as censored at the last time of contact. Survival months were calculated from the date of malignant lymphoma diagnosis to the date of death attributable to this cancer or the last follow-up, whichever came first. Survival months greater than 60 were recoded to 60 in the regression models to analyse the 5-year survival probabilities.

Age was grouped by 20-year intervals (0-19, 20-39, $40-59,60-79$, and 80 or more) due to the distinct disease risk and variation in treatment methods by age. ${ }^{12-14} \mathrm{We}$ classified race/ethnicity as non-Hispanic $(\mathrm{NH})$ white, NH black, Hispanic all races, NH Asian/Pacific Islander (API) and NH American Indian/Alaskan Native (AIAN). Cancer site was classified using the ICD-O-3 sites into four broad groups: oral cavity (lip, C000-C009; tongue, C019C029; salivary gland, C079-C089; floor of mouth, C040C049; gum and other mouth, C030-C039, C050-C059, C060-C069); pharynx (nasopharynx, C110-C119; tonsil, C090-C099; oropharynx, C100-C109; hypopharynx, C129, C130-C139; pharynx, NOS, C140); Waldeyer's ring (C142) and NCS (nasal cavity, C300; sinus, C310-C313, C318-C319). Malignant lymphomas were grouped into NHL, HL and lymphoid neoplasm (LN) according to the lymphoma subtype recode $/{ }^{15}$ WHO.${ }^{15}$ NHLs were further grouped into mature B-cell lymphomas; mature NK/T-cell lymphomas according to the classification by the leukaemia and lymphoma society. ${ }^{16}$ Treatment was grouped into: none; radiation only; surgery only; chemotherapy only; radiation and surgery; chemotherapy and surgery; radiation and chemotherapy and radiation, surgery and chemotherapy. We grouped cancer stages into localised, regional and distant. Year of diagnosis was included in the models as a continuous variable. Countylevel education and income variables were categorised into five levels by quintile.

\section{Statistical analysis}

To evaluate the impact of demographic and prognosis factors on the survival outcome of malignant lymphomas in the OCP region, we used Cox proportional hazard regression models to compute HRs and 95\% CIs with survival month as a time scale. The likelihood ratio $\mathrm{p}$ value was calculated to determine the significance of each variable. $P$ values for trend were calculated by entering the ordinal variable as numeric instead of the original categorical variable into the model. The $\mathrm{p}$ value based on a Wald test of this numeric variable was reported as the $\mathrm{p}$ for trend. Kaplan-Meier curves were used to illustrate the probabilities of survival by certain subgroups over time. Log-rank tests were used to compute the differences in survival probabilities during the follow-up period by subgroups. The interactions between stage and treatment, treatment and lymphoma subtype and stage and lymphoma subtype were examined using Cox regression models. To further explore the difference in factors impacting the survival outcome for lymphomas diagnosed at different 
sites, we conducted subgroup analyses stratified by cancer site (OCP). Limited by the number of cases, Waldeyer's ring and NCS were not analysed as distinct subgroups. Only patients with a complete record of all covariates were included in the regression models. All variables that might have clinical relevance to the survival outcome were included in the models. All statistical tests were two sided, and $\mathrm{p}$ values less than 0.05 were considered statistically significant. All analyses were performed with R software V.4.0.2 (R Foundation, Vienna, Austria). Analysis codes can be found on the following website: https:// githubcom/feifei-CMU-FAH/OCP_NCS_survival_analysis_SEER/blob/main/SA_Rcodes. Institutional review board approval was granted for this study by the First Hospital of China Medical University.

\section{Patient and public involvement}

Patients or the public were not involved in the design, or conduct, or reporting or dissemination plans of our research.

\section{RESULTS}

Of the 8785 malignant lymphoma cases identified in the OCP and NCS regions, 725 (7.62\%) were not included in the models due to missing covariate information. A total of 1784 patient deaths were observed during the study period. Of the 8785 cases included, $3880(44.2 \%)$ were diagnosed in the oral cavity, 3195 in the pharynx (36.4\%), $1599(18.2 \%)$ in the NCS region and 111 in Waldeyer's ring $(1.3 \%)$. The majority of cancers were NHL (95.5\%), followed by LN $(2.6 \%)$ and HL $(1.9 \%)$. The majority of the patients were $\mathrm{NH}$ white $(69.4 \%)$, male $(53.3 \%)$, diagnosed at age $60-79$ years $(42.6 \%)$, diagnosed at the localised stage $(51.5 \%)$ and received chemotherapy only $(19.2 \%)$ (table 1). The median age at diagnosis was 66 years. The median follow-up time was 96 months for patients who were alive or had died of other cancers, and 21 months for those who had died of malignant lymphomas in the OCP or NCS region.

A Kaplan-Meier curve illustrating the survival probabilities of patients stratified by lymphoma subtype demonstrated a statistically significant difference $(\mathrm{p}<0.001)$ in survival probabilities over 5 years (figure 1). The 5-year survival probability was highest for patients diagnosed with HL $(85.89 \%)$ in the OCP or NCS region, followed by those diagnosed with NHL (77.35\%) and LN (67.49\%). This trend was consistent across the study period (figure 1 and table 2 ). When stratified by cancer site, patients diagnosed with malignant lymphomas in the oral cavity exhibited the highest 5-year survival probability (81.05\%), followed by those with malignant lymphomas in the pharynx $(77.50 \%)$, the NCS region $(68.12 \%)$ and Waldeyer's ring $(62.94 \%)$. This trend was also consistent during the study period, demonstrating a statistically significant difference $(p<0.001)$ in survival probabilities across the three site groups (figure 1 and table 2). We also observed statistically significant differences in survival probabilities across cancer staging $(\mathrm{p}<0.001)$ and treatment groups $(\mathrm{p}<0.001)$ (online supplemental figure 1A-1B).

With a multivariable Cox regression model, we found an increased risk of dying from malignant lymphomas in the OCP region for men compared with women $(\mathrm{HR}=1.15$; $95 \%$ CI 1.05 to 1.27$)$, $\mathrm{NH}$ Black patients $(\mathrm{HR}=1.31$; 95\% CI 1.09 to 1.57 ), Hispanic patients (HR=1.32; 95\% CI 1.14 to 1.52) and $\mathrm{NH}$ Asian/Pacific Islander (API) patients (HR=1.37; 95\% CI 1.17 to 1.61$)$ compared with NH White patients. Compared with those with cancers diagnosed in the oral cavity, those with cancers diagnosed in the pharynx $(\mathrm{HR}=1.17 ; 95 \%$ CI 1.04 to 1.31$)$, Waldeyer's ring ( $\mathrm{HR}=1.83 ; 95 \% \mathrm{CI} 1.30$ to 2.57$)$ or NCS region (HR=1.74; 95\% CI 1.54 to 1.98) exhibited a higher hazard of mortality due to malignant lymphoma. Regarding treatment, compared with patients who did not receive any treatment, those who received surgery $(\mathrm{HR}=0.63 ; 95 \% \mathrm{CI}$ 0.51 to 0.78$)$, radiation and surgery ( $\mathrm{HR}=0.46 ; 95 \% \mathrm{CI}$ 0.36 to 0.59 ) or radiation, surgery and chemotherapy (HR=0.76; 95\% CI 0.61 to 0.94 ) showed a lower hazard of mortality. The risk of dying from malignant lymphomas in the OCP or NCS regions increased significantly with age group at diagnosis $(p$ trend $<0.001)$ and cancer stage at diagnosis ( $p$ trend $<0.001)$ and decreased significantly with the year of diagnosis $(\mathrm{p}<0.001)$ (table 2$)$.

Through the utilisation of interaction models, we found evidence of effect modification between treatment and cancer staging at diagnosis of the hazard of mortality ( $p$ interaction $=0.006) \quad($ online supplemental table 1$)$. When stratified by cancer site, similar patterns in the hazard of mortality by covariate groups were observed for the OCP region, except for race/ethnicity. Specifically, compared with $\mathrm{NH}$ white patients, we observed an increased hazard of mortality for NH black (HR=1.59; 95\% CI 1.22 to 2.06), Hispanic (HR=1.49; 95\% CI 1.19 to 1.87$)$ and NH API $(\mathrm{HR}=1.62 ; 95 \% \mathrm{CI} 1.27$ to 2.07$)$ patients whose malignant lymphomas were found in the pharynx. There was no evidence of an association between race/ethnicity and mortality for malignant lymphomas diagnosed in the oral cavity (online supplemental table 2). When stratified by NHL subtypes, the hazard of mortality for mature B-cell lymphoma was associated with gender, age, race/ ethnicity, cancer site, type of treatment, stage at diagnosis and year of diagnosis. The hazard of mortality for mature NK/T-cell lymphoma was associated with cancer site, stage at diagnosis and year of diagnosis (online supplemental table 3).

\section{DISCUSSION}

In the current study, the data of 8785 patients diagnosed with malignant lymphoma in the oral and nasal cavities were analysed using a multivariable Cox regression model. We found that an increase in the 5-year survival rate of malignant lymphoma is associated with: female gender; younger age at diagnosis; $\mathrm{NH}$ white race/ethnicity; diagnosis in the oral cavity; receiving surgery/radiation and surgery/radiation, surgery and chemotherapy as the 
Table 1 Distribution of selected characteristics among patients diagnosed with malignant lymphoma in oral cavity, pharynx, nasal cavity and sinus from 1998 through 2011 overall and by survival status

\begin{tabular}{|c|c|c|c|c|}
\hline \multirow[b]{2}{*}{ Characteristic } & \multicolumn{3}{|l|}{ Number (\%) } & \multirow[b]{2}{*}{ P value* } \\
\hline & $\begin{array}{l}\text { Total } \\
\mathrm{N}=8785\end{array}$ & $\begin{array}{l}\text { Alive or dead of other Causes } \\
\mathrm{N}=7001\end{array}$ & $\begin{array}{l}\text { Dead of malignant Lymphoma } \\
\mathrm{N}=1784\end{array}$ & \\
\hline Gender & & & & 0.200 \\
\hline Female & 4103 (46.7\%) & 3292 (47.0\%) & 811 (45.5\%) & \\
\hline Male & $4682(53.3 \%)$ & $3709(53.0 \%)$ & $973(54.5 \%)$ & \\
\hline Age at diagnosis & & & & $<0.001$ \\
\hline $0-19$ years & $210(2.4 \%)$ & $193(2.8 \%)$ & $17(1.0 \%)$ & \\
\hline 20-39 years & $721(8.2 \%)$ & $606(8.7 \%)$ & $115(6.4 \%)$ & \\
\hline $40-59$ years & $2490(28.3 \%)$ & $2073(29.6 \%)$ & $417(23.4 \%)$ & \\
\hline $60-79$ years & 3744 (42.6\%) & $2980(42.6 \%)$ & $764(42.8 \%)$ & \\
\hline $80+$ years & $1620(18.4 \%)$ & $1149(16.4 \%)$ & $471(26.4 \%)$ & \\
\hline Race/ethnicity & & & & $<0.001$ \\
\hline NH White & $6096(69.4 \%)$ & $4921(70.3 \%)$ & $1175(65.9 \%)$ & \\
\hline NH Black & $635(7.2 \%)$ & $503(7.2 \%)$ & $132(7.4 \%)$ & \\
\hline Hispanic (all races) & $1209(13.8 \%)$ & $942(13.5 \%)$ & $267(15.0 \%)$ & \\
\hline NH API & $802(9.1 \%)$ & $602(8.6 \%)$ & $200(11.2 \%)$ & \\
\hline NH AIAN & $43(0.5 \%)$ & $33(0.5 \%)$ & $10(0.6 \%)$ & \\
\hline Cancer site & & & & $<0.001$ \\
\hline Oral cavity & $3880(44.2 \%)$ & $3216(45.9 \%)$ & $664(37.2 \%)$ & \\
\hline Pharynx & 3195 (36.4\%) & $2550(36.4 \%)$ & $645(36.2 \%)$ & \\
\hline Waldeyers ring & $111(1.3 \%)$ & $75(1.1 \%)$ & $36(2.0 \%)$ & \\
\hline Nasal cavity and sinus & $1599(18.2 \%)$ & $1160(16.6 \%)$ & $439(24.6 \%)$ & \\
\hline Lymphoma subtype & & & & $<0.001$ \\
\hline Non-Hodgkin lymphoma & 8390 (95.5\%) & $6691(95.6 \%)$ & 1699 (95.2\%) & \\
\hline Hodgkin lymphoma & $163(1.9 \%)$ & $142(2.0 \%)$ & $21(1.2 \%)$ & \\
\hline Lymphoid neoplasm & $232(2.6 \%)$ & $168(2.4 \%)$ & $64(3.6 \%)$ & \\
\hline Treatment & & & & $<0.001$ \\
\hline None & $801(9.1 \%)$ & $629(9.0 \%)$ & $172(9.6 \%)$ & \\
\hline Radiation only & $764(8.7 \%)$ & $595(8.5 \%)$ & $169(9.5 \%)$ & \\
\hline Surgery only & $1140(13.0 \%)$ & $973(13.9 \%)$ & $167(9.4 \%)$ & \\
\hline Chemo only & $1687(19.2 \%)$ & $1262(18.0 \%)$ & $425(23.8 \%)$ & \\
\hline Radiation and surgery & $828(9.4 \%)$ & $736(10.5 \%)$ & $92(5.2 \%)$ & \\
\hline Chemo and surgery & $1166(13.3 \%)$ & $923(13.2 \%)$ & $243(13.6 \%)$ & \\
\hline Radiation and chemo & $1510(17.2 \%)$ & $1161(16.6 \%)$ & $349(19.6 \%)$ & \\
\hline $\begin{array}{l}\text { Radiation, surgery and } \\
\text { chemo }\end{array}$ & $889(10.1 \%)$ & $722(10.3 \%)$ & $167(9.4 \%)$ & \\
\hline Stage & & & & $<0.001$ \\
\hline Localised & $4526(51.5 \%)$ & $3814(54.5 \%)$ & $712(39.9 \%)$ & \\
\hline Regional & $2597(29.6 \%)$ & 2049 (29.3\%) & $548(30.7 \%)$ & \\
\hline Distant & $1662(18.9 \%)$ & $1138(16.3 \%)$ & $524(29.4 \%)$ & \\
\hline \multicolumn{2}{|c|}{2000 county $\%<$ high school education } & & & 0.001 \\
\hline $0 \%-13.55 \%$ & $1809(20.6 \%)$ & $1471(21.0 \%)$ & $338(18.9 \%)$ & \\
\hline $13.56 \%-16.78 \%$ & 1776 (20.2\%) & 1425 (20.4\%) & 351 (19.7\%) & \\
\hline $16.79 \%-20.54 \%$ & 1971 (22.4\%) & 1576 (22.5\%) & 395 (22.1\%) & \\
\hline $20.55 \%-29.47 \%$ & 1565 (17.8\%) & 1255 (17.9\%) & $310(17.4 \%)$ & \\
\hline
\end{tabular}

Continued 
Table 1 Continued

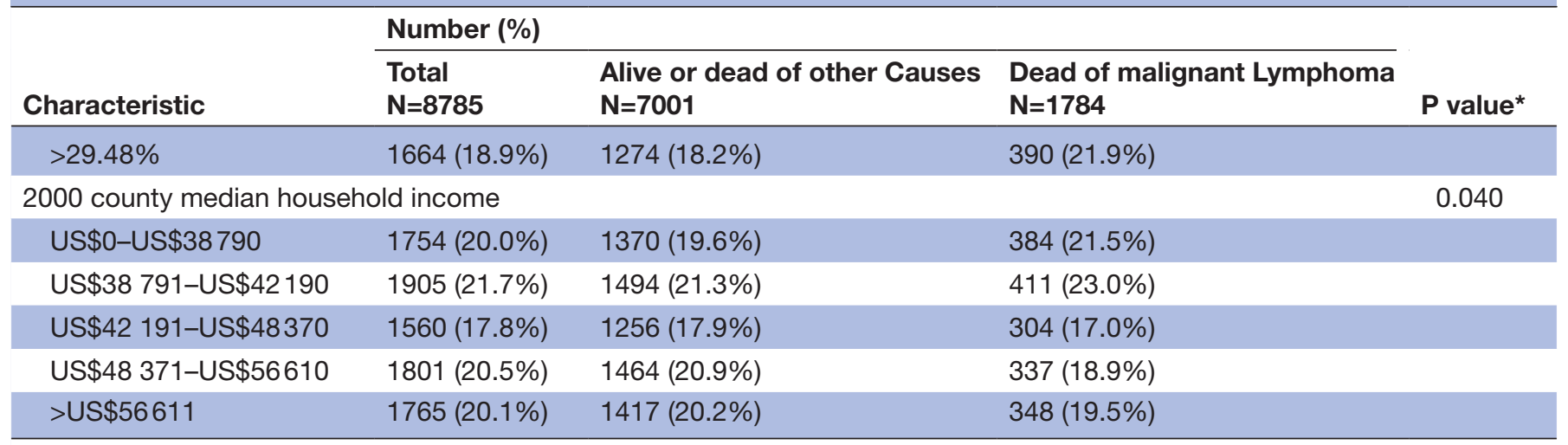

${ }^{*} p$ value according to a univariable log-rank test.

AIAN, American Indian/Alaskan Native; API, Asian, Pacific Islander; NH, non-Hispanic.

treatment; diagnosis at a localised stage and diagnosis in later years. No association with lymphoma subtype (HL and NHL) was observed.

This is the first study to analyse the prognosis factors associated with malignant lymphomas in the oral and nasal cavities in a population-based cancer registry. Several previous studies have reported that the survival rate of malignant lymphomas in the oral cavity worsens with the advancement of clinical stage. ${ }^{417} 18$ Our results are in alignment—we found that the survival rate decreases with advancement in the clinical stage at diagnosis (localised, $82.61 \%$; regional, $76.00 \%$ and distant, $64.22 \%$ at 5 years).

In 2001, Ezzat et al reported that of 130 adult patients with localised lymphomas in the Waldeyer's ring, 58\% survived at a median follow-up of 49 months. ${ }^{19}$ Although Waldeyer's ring is the primary site of NHL involvement, only 111 patients $(1.3 \%)$ with malignant lymphomas in the oral/nasal cavity had tumours found in Waldeyer's ring. In addition, the 5-year (60 month) survival rate for malignant lymphomas in Waldeyer's ring was slightly higher $(62.94 \%)$ than that in the previous report. This is likely to be a result of improvements in management strategies. The combined modality treatment with chemotherapy and radiotherapy for aggressive lymphomas in Waldeyer's ring has been adopted since the $1990 \mathrm{~s},{ }^{13} 14$ which has resulted in a better prognosis and less chance of relapse compared with chemotherapy-only treatment. In addition, the movement to reduce the dose of radiotherapy for early stage lymphomas could also have resulted in a better prognosis for lymphomas diagnosed at early stages. ${ }^{20}$

Worse survival of lymphomas has been reported for low SEP compared with high SEP neighbours. ${ }^{21-23}$ This association is likely to be mediated by treatment. ${ }^{23}$ This is in alignment with the finding in our study that, although the distribution of SEP factors varied by vital status, no statistical significance was observed in the multivariable models with the adjustment of factors including treatment.

Here, we report a difference in the survival rates of malignant lymphomas in the OCP and NCS regions by racial/ethnic group. It was reported by Wu et al that black and API patients had lower incidence rates of B-cell extranodal NHL compared with white patients. ${ }^{24}$ We report a slightly higher 5-year survival rate among $\mathrm{NH}$ white patients $(78.52 \%)$ compared with $\mathrm{NH}$ black (76.41\%), Hispanic $(74.77 \%)$, NH API $(72.26 \%)$ and NH AIAN $(74.87 \%)$ patients. In the multivariable model, NH black patients also exhibited higher hazards of malignant lymphoma death compared with $\mathrm{NH}$ white patients $(\mathrm{HR}=1.31 ; 95 \% \mathrm{CI} 1.09$ to $1.57 ; \mathrm{p}<0.001)$. Despite the lower incidence rates of NHLs among black and API patients, a worse prognosis was observed for patients of these racial/ethnic groups. This is not unique for lymphomas-a lower incidence and worse prognosis among black patients compared with white patients has been observed for many cancers, such as brain tumours, ${ }^{625}$ leukemias, ${ }^{626}$ melanomas, ${ }^{627}$ etc. Regarding melanoma, black patients are more likely to be diagnosed at a later stage compared with patients of other racial/ethnic groups. ${ }^{27}$ However, the associations between the stage at diagnosis and SEP factors by racial/ethnic group remain unclear. Therefore, the racial disparities observed in those cancers warrant greater public health attention on cancer screening and early diagnosis of racial minority patients to achieve a better prognosis. For the current study, no evident difference was observed between the type of treatment or the lymphoma subtype between $\mathrm{NH}$ white and $\mathrm{NH}$ black patients. As a result, further investigation is necessary to understand the underlying reasons driving this racial disparity in the survival of malignant lymphomas found in the OCP and NCS regions.

We also report the variation in prognosis factors that are in association with different NHL subtypes. This result is consistent with the previous report that the survival of nasal type NK/T-cell lymphomas is heavily dependent on the stage at diagnosis. ${ }^{28}$

This study has several strengths and limitations. A major strength is that this was a population-based analysis that included a large cohort of patients with malignant lymphomas diagnosed in the OCP and NCS regions. This 
A.

Strata + Non-Hodgkin lymphoma $\quad+$ Hodgkin lymphoma $\quad$ - Lymphoid neoplasm

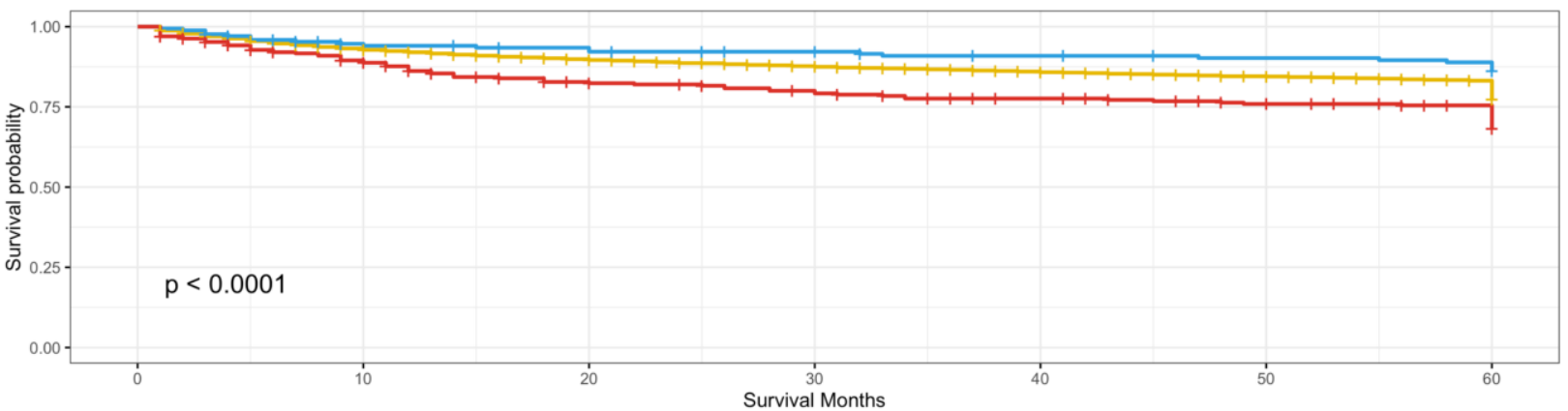

Number at risk: $\mathrm{n}(\%)$

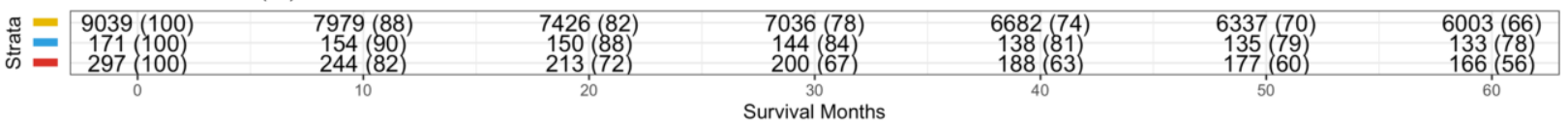

B.

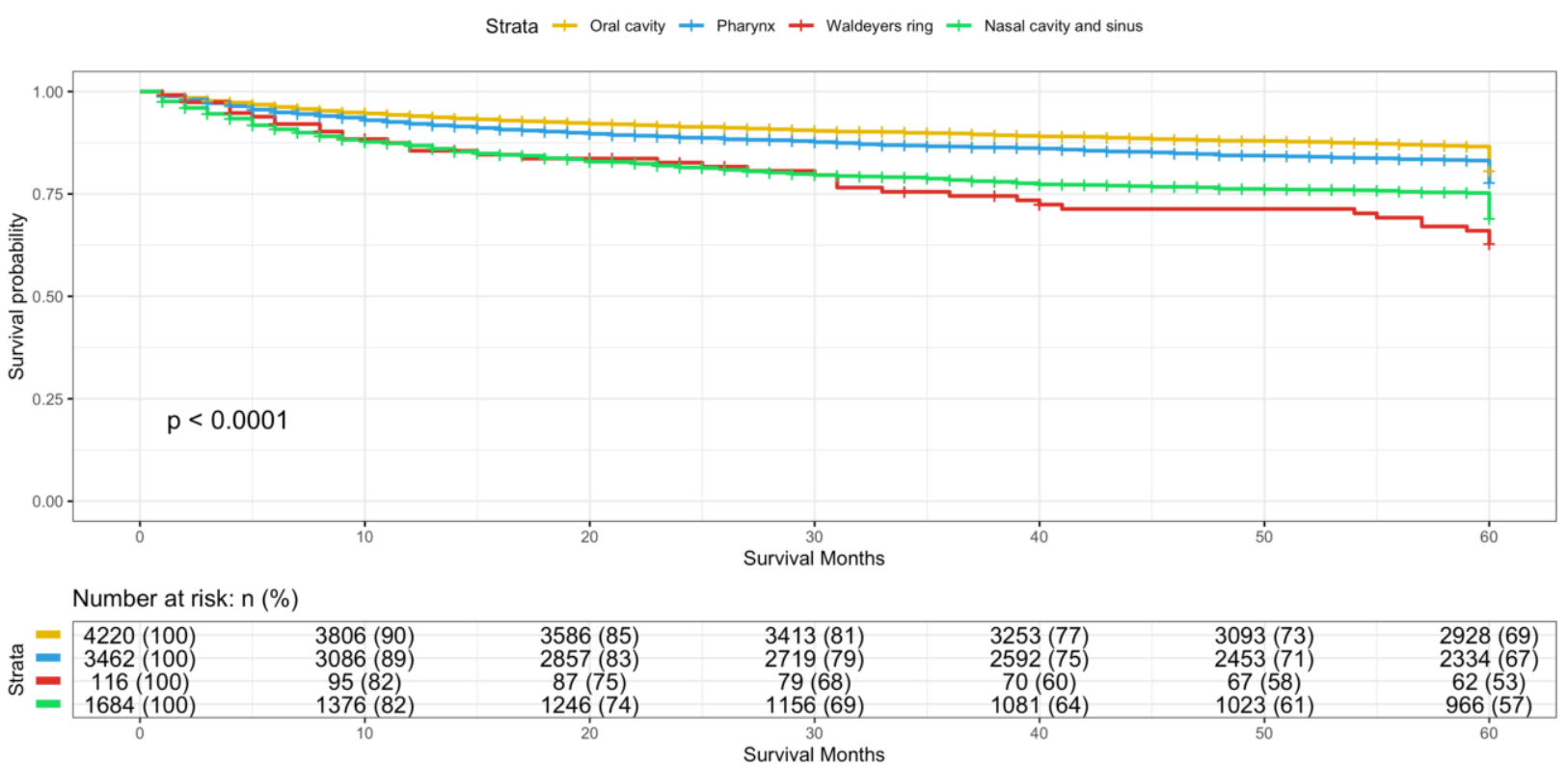

Figure 1 Survival probabilities for patients diagnosed with malignant lymphomas in oral cavity and pharynx from 1998 through 2011. (A) Kaplan-Meier curve illustrating survival probabilities for patients who were diagnosed with Non-Hodgkin lymphoma (yellow line), Hodgkin lymphoma (blue line), and lymphoid neoplasm (red line) in oral cavity and pharynx from 1998 through 2011. The survival probabilities during the five-year follow-up period showed statistically significant difference across the three groups according to a log-rank test $(p<0.001)$. (B) Kaplan-Meier curve illustrating survival probabilities for patients who were diagnosed with malignant lymphoma in the oral cavity (yellow line), pharynx (blue line), Waldeyes ring (red line), and nasal cavity and sinus (green line) from 1998 through 2011. The survival probabilities during the five-year follow-up period showed statistically significant difference across the treatment groups according to a log-rank test $(p<0.001)$.

enabled us to adjust for a set of covariates and perform analyses on subgroups with adequate statistical power. Furthermore, the study benefited from the diverse racial/ ethnic composition of the patient cohort; we were able to evaluate the variation in cancer prognosis by race/ ethnicity, thus making the results generalise to people of various race/ethnic groups. There are some limitations to this study brought about by the use of SEER data. Information on viral infections (EBV, HIV, etc) is absent from SEER data. Thus, the analyses were subjected to residual confounding. In addition, although information on treatment is available in the SEER data, no indicator of the sequence of treatment is available. This prevents us from further investigating the association between treatment and malignant lymphoma survival.

\section{CONCLUSION}

Our study demonstrates that several prognostic and demographic factors are associated with the 5-year survival rate of malignant lymphomas in the oral cavity, pharynx, nasal cavity and sinus regions. Despite the 
Table 2 Risk of malignant lymphoma death for patients diagnosed from 1998 through 2011 by selected characteristics

$\begin{array}{llllll}\text { Characteristic } & \text { Survival at } 2 \text { years (\%) } & \text { Survival at } 5 \text { years }(\%) & \text { HR }(95 \% \mathrm{Cl}) \dagger & \text { P valueł }\end{array}$

Gender

Female

89.02

Male

88.31

77.97

76.65

Age at diagnosis

\begin{tabular}{ll}
\hline $0-19$ years & 96.02 \\
\hline $20-39$ years & 91.74 \\
$40-59$ years & 91.6 \\
$60-79$ years & 89.20 \\
$80+$ years & 79.6 \\
$P$ for trend & \\
\hline
\end{tabular}

Race/ethnicity

NH White

89.31

NH Black

88.19

Hispanic (all races)

87.30

NH API

85.91

$\mathrm{NH}$ AIAN

87.35

Cancer site

Oral cavity

90.69

Pharynx

88.83

Waldeyers ring

80.63

Nasal cavity and sinus

83.65

91.38

82.59

82.33

77.60

60.30

Referent

$1.15^{\star \star}(1.05-1.27)$

ymphoma subtype

Non-Hodgkin lymphoma
Hodgkin lymphoma
Lymphoid neoplasm

88.70

93.15

83.23

Treatment

None
Radiation only
Chemo only
Radiation and surgery
Chemo and surgery
Radiation and chemo
Radiation, surgery and chemo
Stage

86.83

86.31

92.21

84.84

94.41

88.81

87.47

90.45

Stage

$\begin{array}{ll}\text { Localised } & 91.53 \\ \text { Regional } & 88.07 \\ \text { Distant } & 81.46\end{array}$

$P$ for trend§

Year of diagnosis NA

2000 county $\%<$ high school education

\begin{tabular}{llll}
$0 \%-13.55 \%$ & 89.84 & 79.50 & Referent \\
\hline $13.56 \%-16.78 \%$ & 89.02 & 77.96 & $1.02(0.87-1.19)$ \\
$16.79 \%-20.54 \%$ & 88.82 & 77.57 & $1.07(0.92-1.25)$ \\
$20.55 \%-29.47 \%$ & 88.76 & 77.47 & $1.11(0.92-1.34)$
\end{tabular}

Continued

$\begin{array}{ll}78.52 & \text { Referent } \\ 76.41 & 1.31^{\star \star}(1.09-1.57) \\ 74.77 & 1.32^{\star \star}(1.14-1.52) \\ 72.26 & 1.37^{\star \star}(1.17-1.61) \\ 74.87 & 1.44(0.77-2.69)\end{array}$

$<0.001$

$<0.001$

Referent

$1.17^{\star \star}(1.04-1.31)$

$1.83^{\star *}(1.30-2.57)$

$1.74^{\star \star}(1.54-1.98)$

0.175

Referent

$0.87(0.56-1.34)$

$1.26(0.98-1.63)$

$<0.001$

Referent

73.69

$0.96(0.77-1.19)$

$83.92 \quad 0.63^{\star *}(0.51-0.78)$

70.09

$1.09(0.91-1.30)$

88.31

77.38

$0.46^{\star *}(0.36-0.59)$

$0.85(0.70-1.04)$

$74.87 \quad 0.88(0.73-1.07)$

80.50

$0.76^{*}(0.61-0.94)$

Referent

76.00

64.22

$1.40^{\star *}(1.24-1.57)$

$2.22^{\star \star}(1.97-2.50)$

$<0.001$

$0.93^{\star \star}(0.92-0.94) \quad<0.001$

$\begin{array}{lr}\quad N A & 0.93^{\star \star}(0.92-0.94) \quad \\ & 0.001\end{array}$

Referent

$1.07(0.92-1.25)$

$<0.001$

0.321 
Table 2 Continued

\begin{tabular}{|c|c|c|c|c|}
\hline Characteristic & Survival at 2 years (\%) & Survival at 5 years (\%) & HR $(95 \% \mathrm{Cl}) \dagger$ & $P$ value $\neq$ \\
\hline$>29.48 \%$ & 86.58 & 73.45 & $1.23^{*}(1.00-1.50)$ & \\
\hline \multicolumn{2}{|l|}{$P$ for trend§ } & & 0.044 & \\
\hline US\$0-US\$38790 & 87.69 & 75.48 & Referent & \\
\hline US\$38 791-US\$42190 & 87.77 & 75.64 & $0.85^{\star}(0.73-0.98)$ & \\
\hline US\$48 371-US\$56610 & 89.61 & 79.07 & $0.80(0.67-0.95)$ & \\
\hline$>$ US\$56 611 & 89.11 & 78.13 & $0.88(0.74-1.06)$ & \\
\hline$P$ for trend§ & & & 0.080 & \\
\hline
\end{tabular}

${ }^{*} \mathrm{p}<0.05 ;{ }^{* *} \mathrm{p}<0.01$.

†Five-year HR according to a multivariable Cox proportional-hazard model.

$\ddagger P$ value according to a likelihood ratio test.

§P value for trend was calculated by entering ordinal variable as numeric into the model.

AIAN, American Indian/Alaskan Native; API, Asian, Pacific Islander; $\mathrm{NH}$, non-Hispanic.

limitations, the findings of our study are crucial for evoking public health attention on the prognosis of malignant lymphomas in the oral and nasal cavities among the most vulnerable populations as well as illuminating future research directions.

Contributors FJ, A-HY: substantial contribution to the conception and design of the work, manuscript drafting; FJ: acquisition, analysis and interpretation of the data; AHY: revising the manuscript critically, final approval of the version to be published; A-HY: guarantor. All authors have read and approved the final manuscript.

Funding The authors have not declared a specific grant for this research from any funding agency in the public, commercial or not-for-profit sectors.

Competing interests None declared.

Patient consent for publication Not applicable.

Ethics approval The current study does not require IRB review because it involves only publicly available data obtained from the Surveillance, Epidemiology and End Results (SEER) Program. The data are available from National Cancer Institute on request.

Provenance and peer review Not commissioned; externally peer reviewed.

Data availability statement Data are available upon reasonable request. All data used for this analysis are accessible upon reasonable request to the NCI SEER Program: https://seer.cancer.gov/data/sample-dua.html

Supplemental material This content has been supplied by the author(s). It has not been vetted by BMJ Publishing Group Limited (BMJ) and may not have been peer-reviewed. Any opinions or recommendations discussed are solely those of the author(s) and are not endorsed by BMJ. BMJ disclaims all liability and responsibility arising from any reliance placed on the content. Where the content includes any translated material, BMJ does not warrant the accuracy and reliability of the translations (including but not limited to local regulations, clinical guidelines, terminology, drug names and drug dosages), and is not responsible for any error and/or omissions arising from translation and adaptation or otherwise.

Open access This is an open access article distributed in accordance with the Creative Commons Attribution Non Commercial (CC BY-NC 4.0) license, which permits others to distribute, remix, adapt, build upon this work non-commercially, and license their derivative works on different terms, provided the original work is properly cited, appropriate credit is given, any changes made indicated, and the use is non-commercial. See: http://creativecommons.org/licenses/by-nc/4.0/.

\section{ORCID iD}

Feifei Jiang http://orcid.org/0000-0002-9583-3982

\section{REFERENCES}

1 Shankland KR, Armitage JO, Hancock BW. Non-Hodgkin lymphoma. Lancet 2012;380:848-57.

2 Armitage JO, Gascoyne RD, Lunning MA, et al. Non-hodgkin lymphoma. Lancet 2017;390:298-310.

3 International Non-Hodgkin's Lymphoma Prognostic Factors Project. A predictive model for aggressive non-Hodgkin's lymphoma. N Engl J Med 1993;329:987-94.

4 Guevara-Canales J-O, Morales-Vadillo R, Sacsaquispe-Contreras S$\mathrm{J}$, et al. Malignant lymphoma of the oral cavity and the maxillofacial region: overall survival prognostic factors. Med Oral Patol Oral Cir Bucal 2013;18:e619-26.

5 Urquhart A, Berg R. Hodgkin's and non-Hodgkin's lymphoma of the head and neck. Laryngoscope 2001;111:1565-9.

6 Seer cancer statistics review (Csr) 1975-2014: National cancer Institute, 2018. Available: https://seer.cancer.gov/archive/csr/1975_ 2014/

7 Rana K, Narula V, Bhargava EK, et al. T-cell lymphoma of the oral cavity: case report. J Clin Diagn Res 2015;9:MD03-4.

8 Steele TO, Buniel MC, Mace JC, et al. Lymphoma of the nasal cavity and paranasal sinuses: a case series. Am J Rhinol Allergy 2016;30:335-9.

9 Ansell SM. Non-Hodgkin lymphoma: diagnosis and treatment. Mayo Clin Proc 2015;90:1152-63.

10 Shanbhag S, Ambinder RF. Hodgkin lymphoma: a review and update on recent progress. CA Cancer J Clin 2018;68:116-32.

11 National cancer Institute. Radiation/Chemotherapy databases (19752016), 2019. Available: https://seer.cancer.gov/data/treatment.html

12 Lymphoma: centers for disease control and prevention, 2018. Available: https://www.cdc.gov/cancer/lymphoma/index.htm

13 Gustavsson A, Osterman B, Cavallin-Ståhl E. A systematic overview of radiation therapy effects in non-hodgkin's lymphoma. Acta Oncol 2003:42:605-19.

14 Kimby E, Brandt L, Nygren P, et al. A systematic overview of chemotherapy effects in aggressive non-hodgkin's lymphoma. Acta Oncol 2001;40:198-212.

15 National cancer Institute. Lymphoma subtype Recode/WHO 2008, 2008. Available: https://seer.cancer.gov/lymphomarecode/ lymphoma-who2008.html

16 Non-hodgkin lymphoma subtypes: the leukemia \& lymphoma society. Available: https://www.lls.org/lymphoma/non-hodgkin-lymphoma/ diagnosis/nhl-subtypes

17 van der Waal RIF, Huijgens PC, van der Valk P, et al. Characteristics of 40 primary extranodal non-Hodgkin lymphomas of the oral cavity in perspective of the new who classification and the International prognostic index. Int J Oral Maxillofac Surg 2005;34:391-5.

18 Otmani N, Khattab M. Oral burkitt's lymphoma in children: the Moroccan experience. Int J Oral Maxillofac Surg 2008;37:36-40.

19 Ezzat AA, Ibrahim EM, El Weshi AN, et al. Localized non-hodgkin's lymphoma of Waldeyer's ring: clinical features, management, and prognosis of 130 adult patients. Head Neck 2001;23:547-58. 
20 Shah BA, Oh C, Wu SP, et al. Radiation dose reduction in earlystage Hodgkin lymphoma. Clin Lymphoma Myeloma Leuk 2020;20:820-9.

21 Pálmarsdóttir R, Kiesbye Øvlisen A, Severinsen MT, et al. Socioeconomic impact of Hodgkin lymphoma in adult patients: a systematic literature review. Leuk Lymphoma 2019;60:3116-31.

22 Li Y, Sun H, Yan Y, et al. Long-term survival rates of patients with stage III-IV Hodgkin lymphoma according to age, sex, race, and socioeconomic status, 1984-2013. Oncologist 2018;23:1328-36.

23 Frederiksen BL, Dalton SO, Osler M, et al. Socioeconomic position, treatment, and survival of non-hodgkin lymphoma in Denmark--a nationwide study. Br J Cancer 2012;106:988-95.

24 Wu X-C, Andrews P, Chen VW, et al. Incidence of extranodal non-hodgkin lymphomas among whites, blacks, and Asians/
Pacific Islanders in the United States: anatomic site and histology differences. Cancer Epidemiol 2009;33:337-46.

25 Muskens IS, Feng Q, Francis SS, et al. Pediatric glioma and medulloblastoma risk and population demographics: a poisson regression analysis. Neurooncol Adv 2020;2:vdaa089.

26 Feng Q, de Smith AJ, Vergara-Lluri M, et al. Trends in acute lymphoblastic leukemia incidence in the United States by Race/ Ethnicity from 2000 to 2016. Am J Epidemiol 2021;190:519-27.

27 Dawes SM, Tsai S, Gittleman H, et al. Racial disparities in melanoma survival. J Am Acad Dermatol 2016;75:983-91.

28 Haverkos BM, Pan Z, Gru AA, et al. Extranodal NK/T cell lymphoma, nasal type (ENKTL-NT): an update on epidemiology, clinical presentation, and natural history in North American and European cases. Curr Hematol Malig Rep 2016;11:514-27. 